\title{
ENHANCED PROPERTIES OF HYPERBRANCHED POLYURETHANE ELASTOMERS BASED ON POLYDIMETHYLSILOXANE/POLYETHER MIXED SOFT SEGMENTS
}

\author{
YAN MA, QIANYUN TANG, LIHONG WANG AND CHENG YAO* \\ College of Science, Nanjing University of Technology, Nanjing 211816, P. R. China
}

\begin{abstract}
A novel hydroxyl-terminated polymer HPMS-APE was synthesized by introducing allyl polyethylene oxide (APE) into hydrogen-terminated polydimethylsiloxane (HPMS) backbone by hydrosilylation reaction. A series of hyperbranched polyurethane elastomers (HBPUs) based on HMPS-APE and polypropylene glycol (PPG) mixed soft segments were successfully synthesized with trimethylolpropane (TMP) as a chain extender. The effect of HPMS-APE segments content on enhanced properties of HBPUs were characterized by Fourier transform infrared spectroscopy (FT-IR), differential scanning calorimetry (DSC), atomic force microscopy (AFM), thermogravimetric analysis (TGA), mechanical testing and water absorption. It was found that incorporating HPMSAPE in polyurethanes made substantial changes in their morphology, thermal properties, mechanical properties and water absorption. When 5 wt $\%$ HPMS-APE was incorporated in HBPUs, the extent of microphase separation between hard and soft segments was the best, resulting in polyurethanes without significant compromise in tensile strength and elasticity. Furthermore, HBPUs derived from HPMS-APE presented excellent thermal stability and unique water resistance.
\end{abstract}

Keywords: Hyperbranched, Polydimethylsiloxane, Polyurethanes, Microphase separation

\section{INTRODUCTION}

Polyurethanes are multiblock copolymers consisting of alternate hard and soft segments. The hard segments are in a crystalline state or an amorphous glassy state giving materials stiffness and strength, while the soft segments are in a rubbery state giving the elasticity and flexibility. The unique properties of polyurethanes result from both their chemical structure and the extent of microphase separation between hard and soft segments ${ }^{1-4}$.

Recently, to enhance properties of polyurethanes such as thermal stability, water resistance, gas permeability and biocompatibility, polydimethylsiloxanes (PDMS) are widely used for preparing copolymers with polyurethanes because of their excellent properties such as oxidative and hydrolytic stability, good blood contacting properties, a wide service temperature range due to low glass transition temperature $\left(-123{ }^{\circ} \mathrm{C}\right)$, low moisture permeability and low surface energy $^{5-10}$.

However, it has been identified that the major problem associated with synthesizing PDMS-based polyurethanes is the large difference between the solubility parameter of the nonpolar PDMS segments and high polar urethane hard segments, where PDMS as soft segments demonstrates excess degree of microphase separation, yields relatively poor mechanical properties ${ }^{11,12}$ Therefore, a number of methods have been confirmed to improve the phase mixing of these materials. The main approaches reported were to introduce polar functionality into PDMS backbone, or to use blended soft segments of PDMS and polyether-diol ${ }^{13-15}$. At present, some researchers have reported related copolymers, but they mainly concentrate on the studies of linear polyurethanes. For example, Adhikari et al. ${ }^{16,17}$ have demonstrated that when a relatively small amount of a second macrodiol was incorporated as part of the soft segments along with PDMS in linear polyurethanes, the compatibility of the PDMS soft and urethane hard segments could be significantly improved. Lee and coworkers ${ }^{15}$ have reported that the PDMS/polyether mixed soft segments linear urethane membranes had well-phase separated structures. However, no papers can, as yet, be found for detailed studies on properties of PDMSbased hyperbranched polyurethanes. It is known that mechanical properties of hyperbranched polyurethanes are improved by chemical crosslinking process. Hence, it is very interesting to study the properties of hyperbranched polyurethanes modified by PDMS, and it is meaningful to analyze and control bulk properities of the materials.

In this work, a novel hydroxyl-terminated polymer HPMS-APE was synthesized by introducing allyl polyethylene oxide (APE) into hydrogenterminated polydimethylsiloxane (HPMS) backbone by hydrosilylation reaction ${ }^{18}$. The chemical structure of HPMS-APE was confirmed by ${ }^{1} \mathrm{H}$-nuclear magnetic resonance ( $\left.{ }^{1} \mathrm{H}-\mathrm{NMR}\right)$ and Fourier transform infrared spectroscopy (FT-IR). A series of hyperbranched polyurethane elastomers (HBPUs) based on HMPS-APE and polypropylene glycol (PPG) mixed soft segments were successfully synthesized with trimethylolpropane (TMP) as a chain extender. The product formed the crosslinking structures during the chain extension process. The aim of this study was to investigate the effect of HPMS-APE segments content on enhanced properties of HBPUs. The structures of HBPUs were supported by FT-IR. The morphology was investigated by differential scanning calorimetry (DSC) and confirmed by atomic force microscopy (AFM), which provided advantage evidence to the analysis and control the bulk properties. The thermal properties of HBPUs were examined by thermogravimetric analysis (TGA). In addition, the mechanical properties and water absorption were also studied.

\section{EXPERIMENTAL}

\section{Materials}

4, 4'-Methylenediphenyl diisocyanate (MDI) was received from Aladdin chemistry Co., Ltd. and vacuum distilled before use. Polypropylene glycol (PPG, $M_{n}=1000$ ) and allyl polyethylene oxide (APE, $M_{n}=400$ ) were desiccated at $110^{\circ} \mathrm{C}$ before use, which were supplied by Zhongshan Chemical Co., Ltd. (Jiangsu, China). Trimethylolpropane (TMP) was purchased from Sinopharm Chemical Reagent Co., Ltd. (Beijing, China). Hydrogen-terminated polydimethylsiloxane (HPMS, $M_{n}=1000$ ) was self-made. Chloroplatinic acid was received from Nanjing Chemical Reagent Co., Ltd. (Jiangsu, China).

\section{Synthesis of HPMS-APE}

The synthesis of HPMS-APE is shown in Scheme 1. A stoichiometric amount of HPMS and APE (molar ratio of HPMS and APE was 1.0:2.1) with the presence of chloroplatinic acid were added in a $250 \mathrm{~mL}$ flask, and reacted at $120^{\circ} \mathrm{C}$ for $5 \mathrm{~h}$. After the reaction was completed, the mixture was distilled in vacuo at $110^{\circ} \mathrm{C}$ to remove the remaining APE. It was found that the hydroxyl value and acid value of the resulting transparent HPMS-APE were $62.1 \mathrm{mg}$ $\mathrm{KOH} \cdot \mathrm{g}^{-1}$ and $0.32 \mathrm{mg} \mathrm{KOH} \cdot \mathrm{g}^{-1}$, respectively.

\section{Synthesis of HBPUs}

A series of HBPUs were prepared by two-step bulk polymerization without catalyst and additives, which was outlined in Scheme 2. The corresponding compositions are shown in Table 1. All glasswares were dried in an oven overnight at $105^{\circ} \mathrm{C}$.

Prepolymer preparation: HPMS-APE and PPG were charged in a 100 $\mathrm{mL}$ four-necked flask equipped with a mechanical stirrer, a nitrogen inlet, a reflux condenser and a thermometer. The flask was kept at $120^{\circ} \mathrm{C}$ for $2 \mathrm{~h}$ under vacuum to remove traces of water. When the temperature was cooled down to $40{ }^{\circ} \mathrm{C}$, MDI was added into the flask. Then the mixture reacted at $80^{\circ} \mathrm{C}$ for 2 $\mathrm{h}$ under $\mathrm{N}_{2}$ to obtain an isocyanate-terminated polymer having an isocynate content of $6.5 \mathrm{wt} \%$, which was quantitatively determined by the di-n-butyl amine method ${ }^{19}$. 


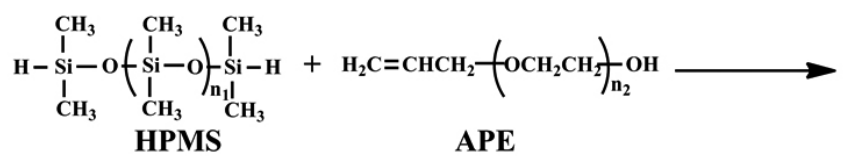

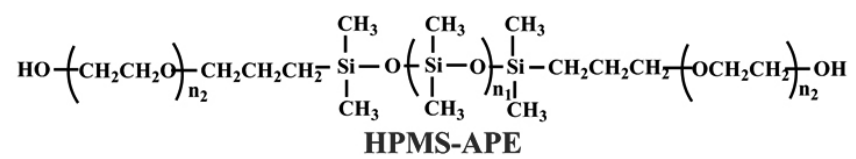

Scheme 1. Synthesis of HPMS-APE.
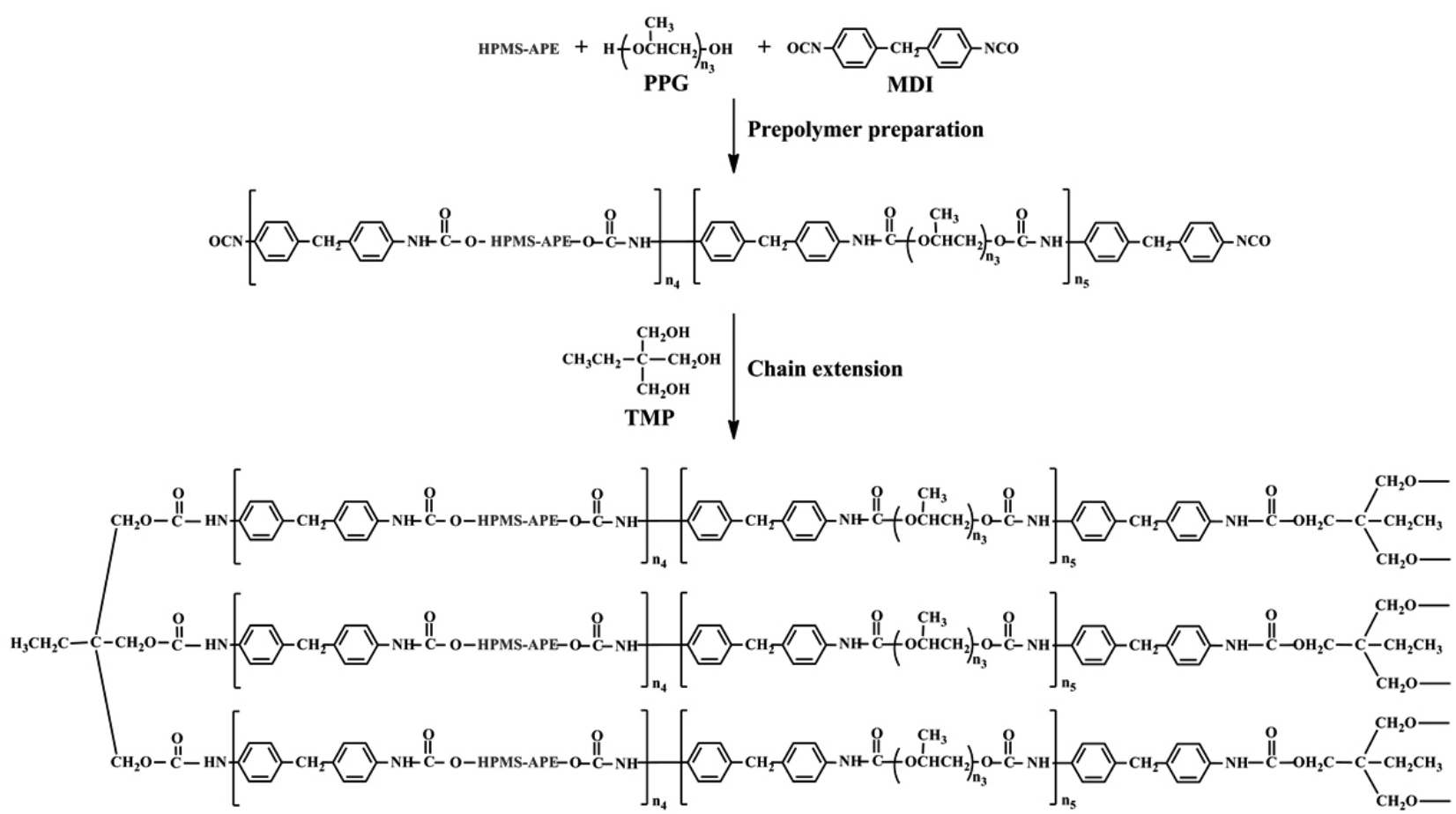

HBPUs

Scheme 2. Preparation of HBPUs.

Chain extension: Following the above-mentioned process, a required amount of TMP was added in the reactor at $80{ }^{\circ} \mathrm{C}$ and stirred vigorously for $2 \mathrm{~min}$. Then the flask was degassed for $10 \mathrm{~min}$ in ultrahigh vacuum to ensure the removal of air bubbles. Finally, the mixture was cast rapidly in a preheated teflon mould to form a $1-2 \mathrm{~mm}$ thick sheet, and cured for $24 \mathrm{~h}$ at $120^{\circ} \mathrm{C}$.

Table 1. Compositions of HBPUs prepared in this study.

\begin{tabular}{|c|c|c|}
\hline Sample & $\begin{array}{c}\text { HPMS-APE/PPG/MDI/TMP (molar } \\
\text { ratio) }\end{array}$ & $\begin{array}{c}\text { HPMS-APE } \\
\text { content (wt } \%)\end{array}$ \\
\hline HBPU0 & $0 / 1.0 / 2.4 / 0.93$ & 0 \\
\hline HBPU1 & $0.05 / 0.95 / 2.4 / 0.93$ & 5 \\
\hline HBPU2 & $0.10 / 0.90 / 2.4 / 0.93$ & 10 \\
\hline HBPU3 & $0.15 / 0.85 / 2.4 / 0.93$ & 15 \\
\hline HBPU4 & $0.20 / 0.80 / 2.4 / 0.93$ & 20 \\
\hline
\end{tabular}

Charaterization and measurements

${ }^{1} \mathrm{H}-\mathrm{NMR}$ spectra of HPMS-APE was recorded with a Bruker $400 \mathrm{MHz}$ spectrometer in deuterated chloroform $\left(\mathrm{CDCl}_{3}\right)$ with tetremethyl silane (TMS) as an internal reference and the operating temperature was $30^{\circ} \mathrm{C}$.

FT-IR spectrum of HBPUs was measured by a FT-IR spectrometer (Nicolet 8700 , Boston, MA) in the wave number of $550-4000 \mathrm{~cm}^{-1}$ at $25 \square$. For each FT-IR spectrum sample, 32 scans were collected in the transmittance mode.

The thermal properties of HBPUs were measured by a DSC 2010 thermal analyzer (TA instrument) with a DSC module, purged with nitrogen gas, and quenched with liquid nitrogen. The specimens were scanned from $-150{ }^{\circ} \mathrm{C}$ to $+200{ }^{\circ} \mathrm{C}$ by a heating rate of $10{ }^{\circ} \mathrm{C} / \mathrm{min}$. The cell was calibrated using an indium standard. The weight of sample was 5-10 mg.

Microphase separation in HBPUs was investigated using a Digital Instruments MultiMode AFM using tapping mode. The images were acquired under ambient conditions using light to moderate tapping.

The thermal stability of HBPUs was investigated using a TGA 2050 (TA instrument). The heating rate was $10{ }^{\circ} \mathrm{C} / \mathrm{min}$ and heated up to $600{ }^{\circ} \mathrm{C}$ under air. The weight of sample was $5-10 \mathrm{mg}$.

The mechanical tests to determine tensile strength, elongation at break and hardness were carried out on dumbbell samples. Tensile strength and elongation at break were determined using an Instron-2380 Universal Testing Machine (Instron Corporation, USA) at a strain rate of $50 \mathrm{~mm} / \mathrm{min}$. Shore hardness was measured on a WHS-150/Shore Hardness Tester (Instron Corporation, USA).

The water absorption was determined as follows. The samples were cut in $3 \mathrm{~cm} \times 1 \mathrm{~cm}$ pieces and dried in a vacuum oven for $24 \mathrm{~h}$ to determine their dry weight $\left(W_{\text {J }}\right)$. Then the sample was immersed in distilled water for $24 \mathrm{~h}, 48 \mathrm{~h}$ and $72 \mathrm{~h}$, followed by wiping off the surface water with a piece of filter paper to determine their weight $(W)$. The water absorption $(W S)$ was then calculated by the formula ${ }^{20}$ :

$$
W S=\left[\left(W_{t}-W_{d}\right) / W_{d}\right] \times 100 \%
$$




\section{RESULTS AND DISCUSSION}

\section{${ }^{1}$ H-NMR and FT-IR spectroscopy}

The chemical structure of HPMS-APE was examined by ${ }^{1} \mathrm{H}-\mathrm{NMR}$ and FTIR. Figure 1 shows several characteristic ${ }^{1} \mathrm{H}-\mathrm{NMR}$ spectra of HPMS-APE. $\delta>5$ ppm did not find absorption peaks, demonstrating that there was no remaining APE in the product. As shown in Figure 2, the typical absorption peaks of polyurethanes at $3300 \mathrm{~cm}^{-1}[v(\mathrm{NH})], 2865-2965 \mathrm{~cm}^{-1}\left[v\left(\mathrm{CH}_{2}\right)\right.$ and $\left.v\left(\mathrm{CH}_{3}\right)\right]$, $1700-1725 \mathrm{~cm}^{-1}[v(\mathrm{C}=\mathrm{O})], 1530 \mathrm{~cm}^{-1}[\delta(\mathrm{NH})]$ and $1070 \mathrm{~cm}^{-1}[v(\mathrm{C}-\mathrm{O}-\mathrm{C})]$ could be seen clearly in the spectra. Compared with FT-IR spectra of HBPU0 based on pure PPG segments, characteristic peaks for HPMS-APE segments in HBPU2 and HBPU4 were clearly noticed. The presence of HPMS-APE in HBPUs was demonstrated by the formation of the absorbance peaks at around $1258 \mathrm{~cm}^{-1}[v$ $\left(\mathrm{CH}_{3}\right)$ in $\left.\mathrm{Si}-\mathrm{CH}_{3}\right], 1000-1100 \mathrm{~cm}^{-1}$ [ $\left.v(\mathrm{Si}-\mathrm{O}-\mathrm{Si})\right]$ and $801 \mathrm{~cm}^{-1}\left(\mathrm{CH}_{3}\right.$-Si rocking). Additionally, characteristic peaks were noticeably stronger as the content of HPMS-APE increased. Finally, FT-IR spectra of all other samples were very similar to above FT-IR results and we confirmed the synthesis of HBPUs based on HMPS-APE and PPG mixed soft segments.

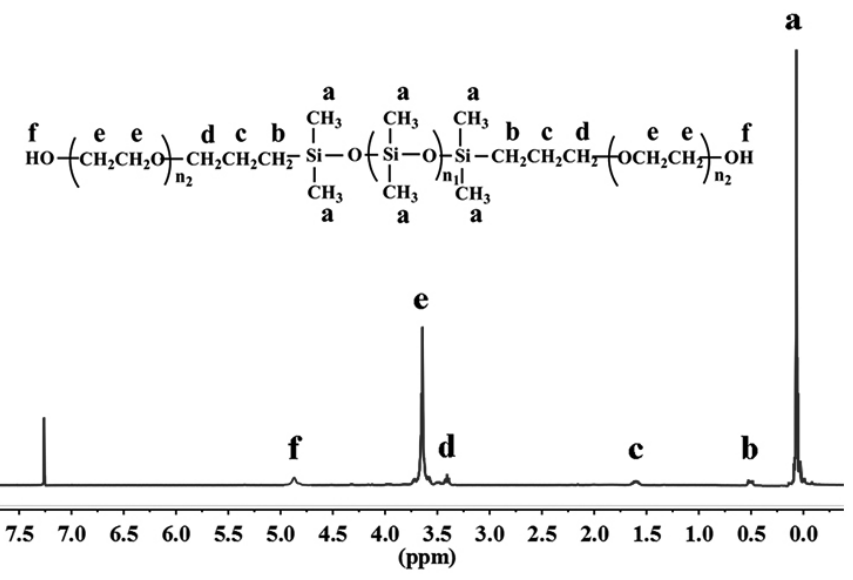

Figure 1. ${ }^{1} \mathrm{H}-\mathrm{NMR}$ spectra of HPMS-APE.

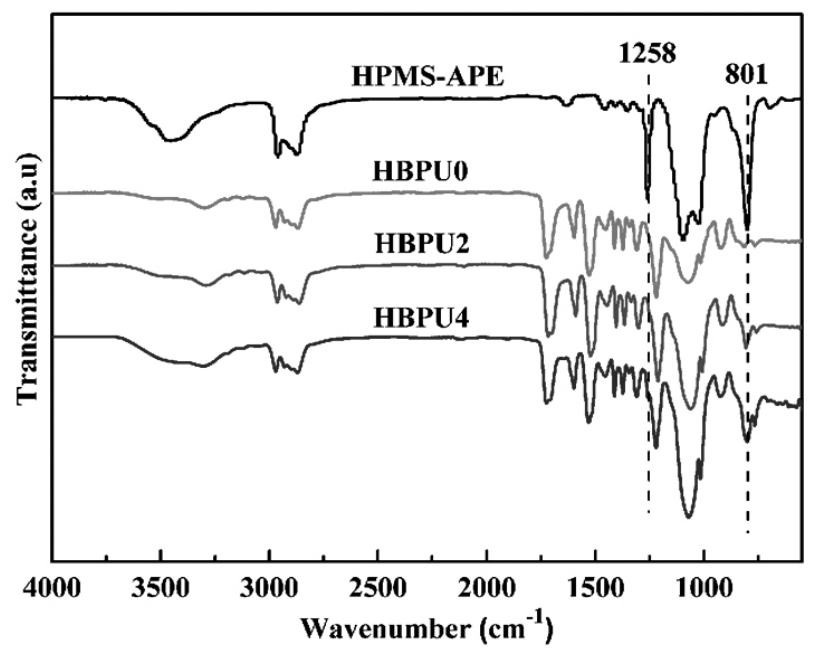

Figure 2. FT-IR spectra of HPMS-APE, HBPU0, HBPU2 and HBPU4.

\section{DSC and AFM analysis}

DSC was used to investigate the morphological effect of HBPUs with different content of HPMS-APE segments. Figure 3 shows the DSC thermograms for HBPUs. In the series, all polyurethanes showed a common melting endotherm $\left(T_{m}\right)$ at around $80{ }^{\circ} \mathrm{C}$, which was assigned to melting of hard segments region derived predominantly from MDI/TMP. The peak of $T$ remained unchanged with increasing HPMS-APE content, while the heat of fusion $(\Delta H)$ for melting endotherms decreased, which was indicative of enhanced phase mixing between hard and soft segments. It was interesting to note that the $\Delta H$ was the lowest for HBPU1 with $5 \mathrm{wt} \%$ HPMS-APE, indicating the most phase mixing of the series. The change in soft segments glass transition temperatures $\left(T_{\mathrm{g}}\right)$ supported this.

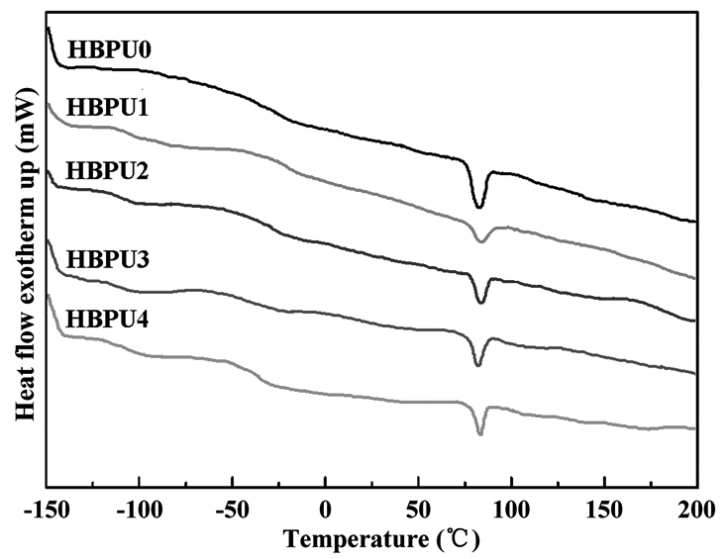

Figure 3. DSC thermograms for HBPUs.

The $T$ of the HPMS-APE and PPG phases are summarized in Table 2. As expected, the $T_{g}$ of the HPMS-APE and PPG phases were clearly identifiable in HBPUs based on mixed soft segments. The $T_{g}$ of HPMS-APE phase varied in a very narrow temperature range as the content of HPMS-APE increased. If there was phase mixing involving HPMS-APE, then the $T$ would be expected to increase significantly ${ }^{10}$. Absence of this demonstrated that HPMS-APE largely remained phase separated. However, the $T$ of the PPG phase varied depending on the content of HPMS-APE. In all cases, except HBPU1, the $T_{\mathrm{s}}$ of the PPG phase in HBPUs was closer to that of HBPU0, which was indicative of relatively more phase separated morphology, and these materials presented low clarity. On the other hand, the $T_{g}$ of the PPG phase in HBPU1 moved to higher temperature, indicating that the PPG phase was present in a most phase mixed state than in the other materials. It was also found that this material was the most transparent. At low level of HPMS-APE (about $5 \mathrm{wt} \%$ ) in the composition, PPG may be more associated with the hard segments and probably concentrated more in the interfacial region ${ }^{16,17}$.

Figure 4 shows the AFM images of HBPUs. According to the principle of tapping mode of AFM operation, the light color areas in Figure 4 represented the hard segments region, and the dark color areas correspond to the soft segments region $^{21}$. Figure 4a shows the AFM image of HBPU0, microphase separation between hard and soft segments can be observed clearly. The congregating hard segments dispersed into the soft phases, but the size of hard segments region was a little bit larger. Figure 4 (b, c, d, e) shows the AFM images of HBPUs with different content of HPMS-APE segments, hard segments region also dispersed into the soft phases, but the size of micro-domain became smaller, because that HPMS-APE segments which were incompatible with hard segments prevented the large hard segments region packing. From Figure $4 \mathrm{~b}$, the hard segments region was more dispersive into the soft phases than the others. In other words, HBPU1 showed a very well microphase separation between hard and soft segments. All those were identical with the analysis results from DSC.
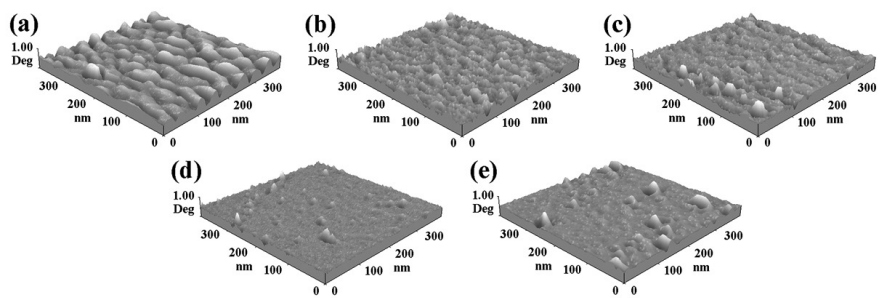

Figure 4. AFM images of HBPU0 (a), HBPU1 (b), HBPU2 (c), HBPU3 (d) and HBPU4 (e). 
Table 2. DSC results for HBPUs.

\begin{tabular}{|c|c|c|c|c|}
\hline Sample & $\begin{array}{c}T_{g} \text { (HPMS-APE) onset, midpoint and endset } \\
\left({ }^{\circ} \mathrm{C}\right)\end{array}$ & $\begin{array}{c}T_{g}(\mathrm{PPG}) \text { onset, midpoint and endset } \\
\left({ }^{\circ} \mathrm{C}\right)\end{array}$ & $T_{m}\left({ }^{\circ} \mathrm{C}\right)$ & $\Delta H\left(\mathrm{~J} \cdot \mathrm{g}^{-1}\right)$ \\
\hline HBPU0 & & $-45.7,-36.9,-22.9$ & 81.3 & 9.94 \\
\hline HBPU1 & $-114.1,-114.8,-101.3$ & $-36.2,-30.1,-18.4$ & 82.0 & 3.42 \\
\hline HBPU2 & $-116.6,-115.7,-102.7$ & $-46.3,-37.1,-24.0$ & 82.1 & 6.43 \\
\hline HBPU3 & $-116.3,-115.0,-102.9$ & $-45.3,-36.2,-23.5$ & 80.4 & 6.51 \\
\hline HBPU4 & $-115.2,-114.3,-101.4$ & $-46.5,-37.3,-24.1$ & 81.8 & 6.07 \\
\hline
\end{tabular}

\section{Thermal stability}

TGA and DTG curves for HBPUs with different content of HPMS-APE are presented in Figure 5. The detailed data of $T_{o n}$ (the temperature at 5\% weight loss), $T_{\operatorname{maxl}}$ (maximum rate of degradation temperature in the first step), $T_{\max 2}$ (maximum rate of degradation temperature in the second step) and $W_{R}$ (residue at $600{ }^{\circ} \mathrm{C}$ ), are summarized in Table 3 . As was known, the first decomposition fraction in the polyurethane chains was the hard segments, which involved the urea and the urethane groups. Decomposition of the soft segments followed the polyester or the polyether. Generally speaking, the decomposition temperature for polyurethanes was at about $240^{\circ} \mathrm{C}$, but for hyperbranched polyurethanes, the decomposition temperature was higher than $300^{\circ} \mathrm{C}^{22,23}$.
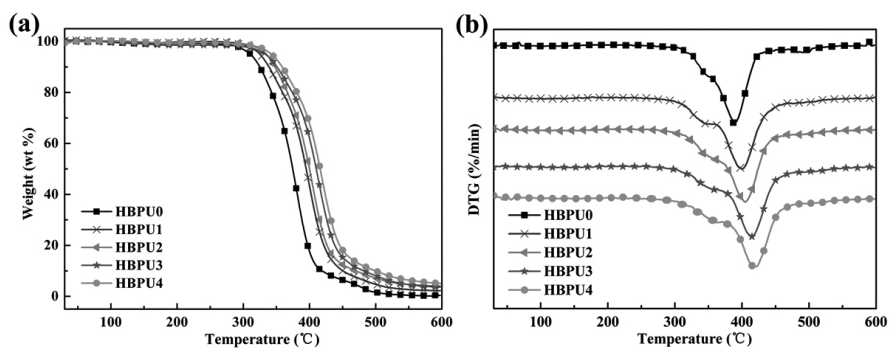

Figure 5. (a) TGA curves of HBPUs, (b) DTG curves of HBPUs.

Table 3. TGA and DTG results for HBPUs.

\begin{tabular}{|c|c|c|c|c|}
\hline Sample & $T_{\text {on }}\left({ }^{\circ} \mathrm{C}\right)$ & $T_{\max }\left({ }^{\circ} \mathrm{C}\right)$ & $T_{\max }\left({ }^{\circ} \mathrm{C}\right)$ & $W_{R}(\%)$ \\
\hline HBPU0 & 320.7 & 344.8 & 387.3 & 0 \\
\hline HBPU1 & 325.1 & 343.6 & 398.4 & 2.3 \\
\hline HBPU2 & 334.2 & 346.6 & 406.0 & 3.6 \\
\hline HBPU3 & 332.9 & 346.9 & 414.7 & 4.0 \\
\hline HBPU4 & 337.0 & 348.1 & 420.1 & 5.1 \\
\hline
\end{tabular}

From the data, it could be seen that the $T$ of HBPUs was about the same up to $320^{\circ} \mathrm{C}$ and the $T_{\text {ol }}$ of HBPUs changed very little, while the $T_{\text {ore }}$ of all HBPUs with HPMS-APE segments were much higher than that of HBPU0 based on pure PPG. The effect of HPMS-APE on the course of degradation was clearly revealed at the second decomposition fraction. The $T_{\max 2}$ of HBPU0 was the lowest and its value was $387.3^{\circ} \mathrm{C}$. The $T$ of HBPUs increased with the growing content of HPMS-APE, and the incorporation of HPMS-APE increased the $T$ as high as $33{ }^{\circ} \mathrm{C}$, which might be ascribed to the greater thermal stability of the HPMS-APE component. In addition, the amount of solid residue after degradation for HBPUs increased to follow the increasing HPMS-APE content. Those findings seemed to serve as the evidence for the formation of complex PDMS-based structures in the pyrolysis process. Their structures were formed on the surface and probably created the insulating layer which slowed down further decomposition of the polymer, as it was observed for PDMS-based polyurethanes ${ }^{24}$.

\section{Mechanical tests}

To evaluate the effect of HPMS-APE segments content on the mechanical properties of HBPUs, tensile tests and Shore hardness tests were performed, as showed in Figure 6a and 6b, respectively. In all cases, the elongation at break of HBPUs gradually increased with increasing HPMS-APE content because of the flexibility of the PDMS. Hardness scores for HBPUs were within the range of $72 \mathrm{~A}$ to $83 \mathrm{~A}$, and there was a tendency for the hardness scores to be lower as the HPMS-APE content increased. However, it was noteworthy that the tensile strength remained largely unchanged up to $5 \mathrm{wt} \%$ of HPMSAPE, yet increasing HPMS-APE above $10 \mathrm{wt} \%$ made HBPUs mechanically weaker than HBPU0 based on pure PPG segments, with HBPU4 showing the lowest tensile strength of the series. Similar observations were reported by $\mathrm{Chen}^{25}$ on the effect of siloxane content on the mechanical properties of PDMS urethanes. The reasons were as follows: the mechanical properties of polyurethanes were profoundly dependent on the degree of microphase separation ${ }^{14}$, and the enhanced phase mixing between hard and soft segments resulted in the best mechanical properties of HBPU1 with $5 \mathrm{wt} \%$ of HPMSAPE, that was in agreement with DSC and AFM analysis. However, when increasing HPMS-APE content above $10 \mathrm{wt} \%$, the tensile strength tended to decrease, resulted from the more HPMS-APE segments content, as well as the excess degree of microphase separation got the negative effect ${ }^{21}$. Compared with previous work on PDMS-based polyurethane materials, in this study, the incorporation of HPMS-APE in polyurethanes can be controlled to a certain degree, polyurethanes could be prepared without significant compromise in tensile strength and elasticity.
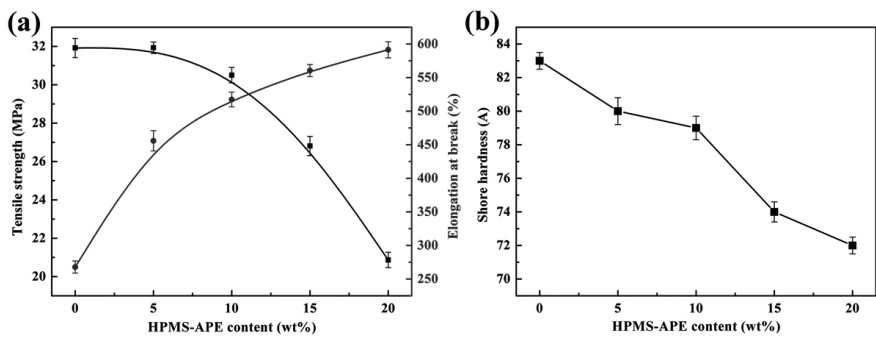

Figure 6. (a) Tensile properties of HBPUs, (b) Shore hardness of HBPUs.

\section{Water absorption testing}

As shown in Figure 7, it was found that the water absorption for HBPUs had an obvious decrease with the addition of HPMS-APE, when the content of HPMS-APE increased from $0 \mathrm{wt} \%$ to $20 \mathrm{wt} \%$, the water absorption of HBPUs decreased from $11.28 \%$ to $0.73 \%(72 \mathrm{~h})$. Moreover, with the incorporation of HPMS-APE, the water absorption for HBPUs based on mixed soft segments kept mostly unchanged above $48 \mathrm{~h}$ in comparison with HBPU0. In this study, $0-20 \mathrm{wt} \%$ of HPMS-APE content was incorporated in polyurethanes, so the degree of microphase separation didn't influence the water resistance of HBPUs ${ }^{26}$, and HPMS-APE content appeared to be the sole factor. Due to the strong hydrophobic Si-O-Si bonds and the low surface energy of HPMS-APE segments, polyurethanes had a highly hydrophobic nature, and it brought polyurethanes good hydrolytic stability and fast water release on drying ${ }^{27}$. Further, the water resistance of these materials was superior to that of previously published PDMS-based polyurethanes ${ }^{21,22}$. Accordingly, we confirmed that HBPUs derived from HPMS-APE presented excellent water resistance.

\section{CONCLUSIONS}

In summary, a series of HBPUs base on HMPS-APE and PPG mixed soft segments were successfully synthesized. The enhanced properties of HBPUs with different content of HMPS-APE segments were characterized by FT-IR, DSC, AFM, TGA, mechanical testing and water absorption. DSC and AFM results confirmed that the incorporation of HMPS-APE as part of the soft segments resulted in enhanced phase mixing between hard and soft segments, and HBPU1 with 5 wt $\%$ HMPS-APE appeared to be the most extent of microphase separation between hard and soft segments of the series. Mechanical testing results clearly demonstrated that incorporating $5 \mathrm{wt} \%$ HMPS-APE, polyurethanes could be prepared without significant compromise 
in tensile strength and elasticity. Furthermore, TGA results indicated that incorporating HMPS-APE in polyurethanes made substantial changes in their thermal stability, increasing $T_{\text {max }}$ as high as $33^{\circ} \mathrm{C}$ in comparison with HBPU0 based on pure PPG. Additionally, HBPUs derived from HPMS-APE presented excellent water resistance, when HPMS-APE increased from $0 \mathrm{wt} \%$ to $20 \mathrm{wt} \%$, the water absorption of HBPUs decreased from $11.28 \%$ to $0.73 \%(72 \mathrm{~h})$.

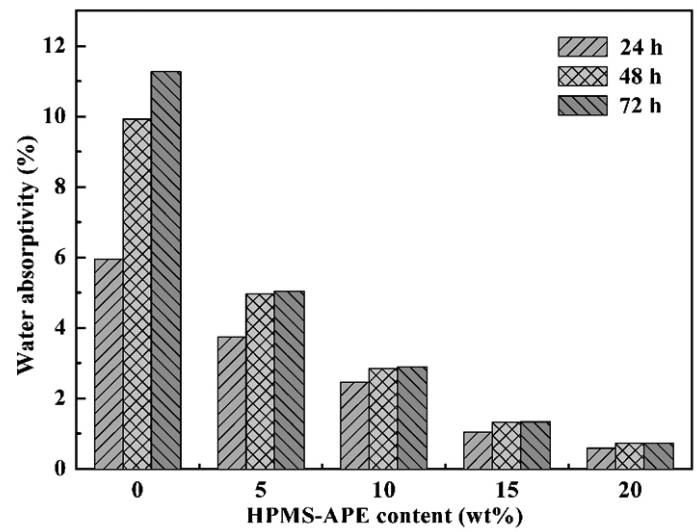

Figure 7. Water absorption of HBPUs.

\section{ACKNOWLEDGEMENTS}

Financial support from the 863 program (2011AA02A204) is acknowledged.

\section{REFERENCES}

1. C. W. Mense, X. Z. Yang, D. C. Yang, S. L. Hsu, Macromolecules 25, 925, (1992)

2. K. Kojio, Y. Mitsui, M. Furukawa, Polymer 50, 3693, (2009)

3. M. M. Demir, I. Yilgor, E. Yilgor, B. Erman, Polymer 43, 3303, (2002)

4. P. F. Yang, Y. D. Han, T. D. Li, J. Y. Li, Chin. Chem. Lett. 21, 853, (2010)

5. M. M. Rahman, A. Hasneen, H. D. Kim, W. K. Lee, J. Appl. Polym. Sci $125,88,(2012)$

6. J. C. McDonald, G. M. Whitesides, Accounts Chem. Res. 35, 491, (2002)
7. D. J. Martin, L. A. Poole Warren, P. A. Gunatillake, S. J. McCarthy, G. F. Meijs, K. Schindhelm, Biomaterials 21, 1021, (2000)

8. J. J. Hoffman, C. M. Leir, Polym. Int. 24, 131, (1991)

9. K. Madhavan, B. S. R. Reddy, J. Polym. Sci. Pol. Chem. 44, 2980, (2006)

10. J. P. S heth, A. Aneja, G. L. Wilkes, E. Yilgor, G. E. Atilla, I. Yilgor, F. L. Beyer, Polymer 45, 6919, (2004)

11. T. Su, G. Y. Wang, X. D. Xu, C. P. Hu, J. Polym. Sci. Pol. Chem. 44, 3365, (2006)

12. M. Kajiyama, M. A. Kakimoto, Y. Imai, Macromolecules 23 , 1244, (1990)

13. C. Z. Yang, C. Li, S. L. Cooper, J. Polym. Sci. Pol. Phys. 29, 75, (1991)

14. X. Yu, M. R. Nagarajan, C. Li, P. E. Gibson, S. L. Cooper, J. Polym. Sci. Pol. Phys. 24, 2681, (1986)

15. H. B. Park, C. K. Kim, Y. M. Lee, J. Membrane Sci. 204, 257, (2002)

16. R. Adhikari, P. A. Gunatillake, S. J. Mccarthy, G. F. Meijs, J. Appl. Polym. Sci. 78, 1071, (2000)

17. R. Adhikari, P. A. Gunatillake, M. Bown, J. Appl. Polym. Sci. 90, 1565, (2003)

18. C. H. Blevins, W. B. Herdle, G. J. Murphy, US 4814409, 1989

19. D. J. David, H. B. Staley, Analytical Chemistry of Polyurethanes, WileyInterscience, New York, 1969

20. J. M. Yang, H. T. Lin, W. C. Lai, J. Membrane Sci. 208, 105, (2002)

21. J. Liu, Z. Q. Pan, Y. Gao, J. Appl. Polym. Sci. 105, 3037, (2007)

22. C. Y. Bai, X. Y. Zhang, J. B. Dai, J. H. Wang, J. Coat. Technol. Res. 5, $251,(2008)$

23. P. Króla, K. Pielichowska, Ł. Byczyński, Thermochim. Acta 507, 91, (2010)

24. L. F. Wang, Q. Ji, T. E. Glass, T. C. Ward, J. E. McGrath, M. Muggli, G. Burns, U. Sorathia, Polymer 41, 5083, (2000)

25. R. S. Chen, C. J. Chang, Y. H. Chang, J. Polym. Sci. Pol. Chem. 43, 3482, (2005)

26. M. S. Yen, P. Y. Tsai, J. Appl. Polym. Sci. 90, 233, (2003)

27. X. R. Li, G. Q. Fei, H. H. Wang, J. Appl. Polym. Sci. 100, 40, (2006) 